\title{
EXPLORING THE IDEAL OF TEACHING AS CONSUMMATORY EXPERIENCE
}

\author{
Sevket Benhur Oral
}

\begin{abstract}
In this article, it is argued that fulfilling teaching and educative experiences go hand in hand. Not only is it possible to be fully alive as a teacher, it is also essential for educative experience to unfold in students. To substantiate the claim made here, an analysis of what I would like to call the ideal of teaching as consummatory experience is engaged based on John Dewey's concept of experience as this was elucidated in his later works, especially Art as Experience. Given an intimate understanding of Deweyan consummatory experience, its implications for teaching and teacher education programs are considered.
\end{abstract}

\section{INTRODUCTION}

In this paper, I intend to discuss what I would like to call "the ideal of teaching as consummatory experience" in relation to John Dewey's concept of "experience," as the latter was elucidated in his later works, especially Art as Experience. What I have in mind with the phrase "the ideal of teaching as consummatory experience" basically points to what it means to be fully alive as a teacher and what happens when teaching is experienced in such a manner. In other words, what is the relationship between teaching that is truly fulfilling for the teacher and experience that is truly educative for the student(s)? There is no doubt in my mind that the two are intimately connected. Truly fulfilling teaching and truly educative experience go hand in hand. It is not only possible to be fully alive as a teacher, it is also essential for educative experience to unfold in students.

In very general terms, educative experience is about being connected with the world in a meaningful manner. It is about making sense of things. As a teacher, when you experience the world and therefore yourself with a heightened sense of meaning, you provide the essential condition for creating educative experience for your students.

The relevance of this work lies in the fact that most of us (teachers) do not experience teaching in a fulfilling manner most of the time. There is no significant heightened sense of meaning in what we are doing. More often than not, teaching becomes 


\section{Sevket Benhur Oral}

a routinized activity and turns into a deadening experience, not only for us but for our students as well. This, in turn, leads to miseducative experience in our students.

In order to experience teaching with a heightened sense of meaning, that is, in order to feel integrally connected with our students, our surroundings, and ultimately with ourselves, we as teachers have to be in touch with the world we live in. We are in touch with our world when we actively participate in it. When we risk touching and being touched, we fully participate in the unfolding drama that is life. When we have the courage to go out there and engage, we experience life with a heightened sense of meaning. We are not in touch with our world when we are merely spectating. We are not in touch with our world when we cringe in fear in the face of it.

Being in touch with the world requires a deliberate interaction with the world with an attitude of openness, and this entails a sense of trust. The world is the locus of meaning. This meaning, however, is not always simply given and transparent. It needs to be understood and interpreted by the individual. It requires a sustained effort on our part to be willing to engage with it, and not just once but at all times. In the process of engaging with the world as a locus of meaning, ambiguities, uncertainties, disruptions, confusions, and anxieties are encountered. Despite these difficulties, we maintain our trust in the world and in our ability to engage with it in the most fulfilling way possible.

Such an attitude of openness does not emerge of its own accord. It is something that needs to be brought into existence and deliberately cultivated in each individual. This is the goal of educative experience. When experience is educative, the individual is open to the world in such a way that her interactions with it provide a heightened sense of meaning. Similarly, providing an environment that makes the formation and cultivation of such an attitude possible in teachers is the goal of teacher education. To attain this goal, I argue, we need a broad liberal arts and sciences education that is firmly rooted in practice. We cannot be in touch with the world with an attitude of openness merely by acquiring some narrowly defined technical skills designed to manipulate a limited sector of this world. We cannot be in touch with the world with an attitude of openness just by cogitating about it in isolation. The goal of teacher education programs should be to help teachers engage in their own self-formation, to become individuals who do not fear to be open to the world as a locus of meaning.

In attempting to articulate what it means to be fully alive as a teacher, I will draw on my own journey of teaching and learning, as well as the works of one of the most eminent American philosophers, John Dewey. As a prominent thinker, and a great educational philosopher more specifically, Dewey continues to exert an enormous influence on our thinking regarding education and our times. It is my conviction that in order to comprehend what it means to be fully alive as a teacher we must strive to come to terms with his thought, and to understand it anew. 
This work, then, is a contribution to the very process of understanding Dewey anew in the context of the experience of teaching. The call for a renewed understanding of Dewey is especially relevant since Dewey's later works, in particular, Art as Experience, bring his commitment to be fully alive in the world into sharp focus. It is important to realize that Dewey's concept of "consummatory experience," that is, experience in its most fulfilling form, and his understanding of what makes experience educative are intimately related to one another. ${ }^{1}$ The present work is meant to bring out the significance of this intimate relationship.

The originality of this work lies in its focus on the experience of teachers. A philosophical discussion of the Deweyan concept of consummatory experience from the perspective of teachers has not been attempted before. Dewey's own articulation of what constitutes educative experience is very well known. When the object of philosophical analysis is educative experience, Dewey scholars (including Dewey himself) focus on students. When the object is consummatory experience, I argue, the focus should be the experience of teachers.

In this article, I will first briefly discuss Dewey's concept of consummatory experience, especially focusing on what he means by "an enveloping undefined whole." The relationship between the consummatory experience of teaching and educative classroom experience will be taken up next. Here, I will particularly zero in on the temporal unfolding of experience and the role of reflection when situations become problematic. Then, I will consider what being and becoming a teacher entails, given the understanding of the role of consummatory experience, in shaping educative classroom experience. I will conclude by discussing the implications of consummatory experience for teaching and teacher education programs.

\section{Dewey's Concept of Consummatory ExPerience}

The aesthetic, for Dewey, "marks the fulfillment of the impulsion of the self toward embodied meaning and value" ${ }^{2}$ which is realized within a pervasive qualitative whole. Dewey contends that through the aesthetic

[w]e are, as it were, introduced into a world beyond this world which is nevertheless the deeper reality of the world in which we live in our ordinary experiences. We are carried out beyond ourselves to find ourselves... the work of art operates to deepen and to raise to great clarity that sense of an enveloping undefined whole that accompanies every normal experience. This whole is then felt as an expansion of ourselves. ${ }^{3}$

The world we are introduced into through the aesthetic is the world of ordinary experience, except here our activities "are directed toward achieving and sustaining experiences which make life an integrated, significant, and organized whole."' The deeper reality of our ordinary everyday world is not a different world. The deeper reality of our ordinary everyday world is not a metaphysical world. The 


\section{Sevket Benhur Oral}

deeper reality of our ordinary everyday world is this world. It is the same world experienced in a unified fulfilling way. The fragmentary and, therefore, anaesthetic everyday world is transformed into an aesthetic integrated this world through understanding of the way the pervasive qualitative whole functions.

For Dewey, ordinary experience is seen to be fractured, fragmented, unfulfilling, and meaningless when it is not lived with an openness to and awareness of a sense of "an enveloping undefined whole." For him, the aesthetic is an intense realization of the presence of this enveloping undefined whole in all experience. ${ }^{5}$ Dewey contends that this realization is not something mysterious or strange, although it might initially feel that way since our ordinary experience is oftentimes dispersed and distracted, devoid of a sense of unity and wholeness. It is Dewey's claim that the presence of this enveloping undefined whole sets the very possibility for everyday experience to take on the quality of integrated fulfillment.

Through the presence of this quality of integrated fulfillment, mundane experience is shaped itself into what Dewey calls "an experience."

We have an experience when the material experienced runs its course to fulfillment. Then and then only is it integrated within and demarcated in the general stream of experience from other experiences. A piece of work is finished in a way that is satisfactory; a problem receives its solution; a game is played through; a situation, whether that of eating a meal, playing a game of chess, carrying on a conversation, writing a book, or taking part in a political campaign, is so rounded out that its close is a consummation and not a cessation. Such an experience is a whole and carries with it its own individualizing quality and self-sufficiency. It is an experience. ${ }^{7}$

Dewey is very much disturbed by the fact that most experience does not constitute "an experience." That is, our lives mostly consist of an unconsummated series of occasions where "an experience" is never realized. Consummation, for Dewey, "is not merely a terminus or an ending, but a moment which brings a process to fulfillment: it is the outcome of a guided process of action which organizes and unifies the experience... Such experiences are the realization of a temporal process and are unified by a distinctive quality." qualitatively unified temporal process having its own beginning and end is the structure of the kind of world we live in. The world we live in does not consist of a "uniform uninterrupted march or flow." Rather, "it is a thing of histories, each with its own plot, its own inception and movement toward its close, each having its own particular rhythmic movement; each with its own unrepeated quality pervading it throughout." ${ }^{\prime 10}$

"An experience" cannot be characterized as an uninterrupted undifferentiated uniform flow. Nevertheless, it is a flow organized in such a way that an intense sense of an integrating quality reveals a dimension of the meaning of human life. The flow is composed of distinct phases which are, nevertheless, organized into 
a continuity that "coherently relates and connects the phases so that the outcome will be the end of a process and not an isolated, meaningless event:"11

Because of continuous merging, there are no holes, mechanical junctions, and dead centers when we have an experience. There are pauses, places of rest, but they punctuate and define the quality of movement. They sum up what has been undergone and prevent its dissipation and idle evaporation.... In a work of art, different acts, episodes, occurrences melt and fuse into unity, and yet do not disappear and lose their own character as they do so-just as in a genial conversation there is a continuous interchange and blending, and yet each speaker not only retains his own character but manifests it more clearly than is his wont. An experience has a unity that gives it its name, that meal, that storm, that rupture of friendship. The existence of this unity is constituted by a single quality that pervades the entire experience in spite of the variation of its constituent parts. This unity is neither emotional, practical, nor intellectual, for these terms name distinctions that reflection can make within it. ${ }^{12}$

The enveloping undefined whole-which cannot be reduced to the sum of its parts-endures in its successive phases, which are constituted by the temporal development of an underlying quality as the source of embodied meaning and value. When such a quality is not engaged, "the experience had is inchoate. Things are experienced but not in such a way that they are composed into an experience. There is distraction and dispersion; what we observe and what we think, what we desire and what we get, are at odds with each other."13 Unconsummated experience, either in the form of an aimless drift or mechanical efficiency, comes to an end but not to a close or consummation in consciousness. What makes an experience consummatory is the possession of an "internal integration and fulfillment reached through ordered and organized movement." 14 Not only is there a sense of direction here, there is also a sense of how the individually demarcated phases and activities are interconnected. An experience is not an oceanic state of bliss. On the contrary, there are tensions and obstacles, but these are overcome in such a way that they feed the overall growing meaning of experience as it unfolds "toward an end that is felt as accomplishment of a process." 15

The end, however, is not necessarily a happy ending. As Dewey mentions in the passage quoted above, "that rupture of friendship" can be as much an experience as, say, a first-rate translation of Dewey's Art as Experience into Turkish [which I intend to undertake in the near future]. The rupture of a friendship can be a consummatory experience and, hence, pervaded by an aesthetic quality despite its undesirable conclusion, to the extent that it exemplifies wholehearted action with a sense of what it has been about. Such a sense is achieved because the successive parts constituting the experience are not connected with one another only mechanically from outside; rather, they are composed into a unity that has a 


\section{Sevket Benhur Oral}

developing movement toward its own consummation. The consummatory unity Dewey has in mind is not a timeless unity. Rather,

it is an affair of temporal development. Not only is there progression, but there is progressive integration which gathers the temporal phases together as belonging, relating to each other, sustaining and interacting with each other in a tensive, dramatic unity so that there is a cumulative sense of an overall event being accomplished or brought to completion. Each phase or moment must be grasped as a phase or part of a larger whole; the sense of the whole must be present in the part. While in most experiences the unifying qualitative sense of the whole, which ultimately constitutes the horizon of meaning, is left tacit, in an experience this is consciously apprehended and realized so that the sense of the experience is the presence of its meaning, felt as a guiding, controlling qualitative unity pervading all the various parts in their variety. ${ }^{16}$

The reason the unifying qualitative sense of the whole is mostly not consciously experienced is that "rigid abstinence, coerced submission, tightness on one side and dissipation, incoherence and aimless indulgence on the other, are deviations in opposite directions from the unity of an experience." ${ }^{17}$ This suggests that the potential for any mundane experience to be an experience is always present to the extent that the anesthetic is dispelled.

\section{The Dialectical Relationship BETWEen “CONSUMMatory Experience of Teaching" and "Educative Classroom Experience"}

In this section, an attempt will be made to explicate the connection between, on the one hand, the philosophical exposition of Dewey's concept of experience and its temporal and hence consummatory nature, and, on the other, education as it is experienced by a teacher in a classroom situation. Accordingly, it shall be argued that only when the experience of teaching is consummatory, that is, when it is already imbued with a unified heightened sense of meaning, can classroom experience become truly educative, that is, meaningful.

Put negatively, unless the experience of teaching is consummatory, classroom experience eventually degenerates into miseducative (anesthetic, routinized, dull, mechanical, lifeless, numbed, mindless) experience, that is, experience that no longer grows. It has to be remarked early on that in this article I attempt to elucidate the ideal of teaching as consummatory experience. Just as an aesthetically integrated experience of the world is not necessary to lead a fairly satisfactory mundane life devoid of a heightened sense of unity and meaning, the experience of teaching does not necessarily need to be consummatory for classroom experience to be educative. Naturally, some form of teaching and learning still takes place short of the ideal situation, which is indeed rare. Yet understanding the nature and structure 
of consummatory experience, as Dewey understands it, contributes to the efforts to increase the likelihood of the emergence of a pedagogical situation which is experienced in a consummatory fashion. The concept of consummatory experience functions as an orienting principle that can guide the design and implementation of teacher education reform programs.

The relationship between the consummatory experience of teaching and the educative classroom experience is dialectical, which is to suggest that a straightforward causal relationship between the two never obtains. Dewey's notion of experience definitively rules out the possibility of an overly simplistic causal relationship between the experience of teaching and learning. In Dewey's philosophy of experience, teaching and learning are reciprocally constitutive of each other. The transaction between teaching and learning is "a single structure, not two separate, discrete structures which somehow causally 'act' upon one another."18

The consummatory experience of teaching, in other words, does not cause educative classroom experience to take place. That is, teaching does not cause learning for meaning is not a spatial object transferred from one place to another. It is not as if, first, the teacher has a consummatory experience within herself, whereby a heightened sense of meaning is obtained and secured, and then she transmits the essence of this experience, this meaning, to her students as part of her job (and gets paid for it based on how many objects and at what rate she transfers them, since these objects are spatial and spatial only, we can absolutely quantify them as well as their transfer rate and therefore can calculate how much we need to pay the teacher). This conception of meaning as a spatial object rather than a temporally unfolding event prevents us from understanding humans as sense-giving beings "on a level of experience which precedes, or is prior to, the conscious positing of distinct objects of cognitive awareness." ${ }^{19}$

According to Dewey, experience does not have an exact location. It is not primarily a spatial affair. It is temporal. In the context of teaching and learning, this means that meaning is not a circumscribed object of cognition to be moved around. Rather, it is situational. Meaning is a temporally complex field experience. It does not first take place in the mind of the teacher and then is transferred to the minds of the students. This mentalistic sense of teaching and learning is hopelessly simplistic and exceedingly misleading. Education is situational because meaning is situational. Teaching and learning as a dialectical process of making meaning happens in a situation. One does not cause the other. It is not a causal relationship. Rather, it is a happening, a lived experience that unfolds in time. Dewey describes the process of the emergence and transformation of meaning in time in terms of situations. It is about how meaning is experienced in time. It is not about knowledge and information per se as time-free objects of disinterested static cognition destined for categorization, classification, storage and manipulation; it is about lived meaning that unfolds in time. 
At this juncture, it is helpful to interpret the concepts "consummatory experience of teaching" and "educative classroom experience" as constituting the opposing poles of a single dynamically unfolding unified field process of meaning. Consummatory and educative experiences, in short, are about meaning, that is, meaningful experience. Such experience cannot be spatialized and taken out of a temporal context, that is, meaningful experience is not something (like a loaf of bread) that can be set on a kitchen table and sliced up when needed. The bread does not just sit there forever; it eventually goes bad, for at no point in time is it alone sitting there by itself. It is never a spatial object in isolation. It is always part of an organic, transactional dynamic whole that is constantly undergoing change.

According to Dewey, experience is meaningful only when the rhythm of experience is allowed to run its course unimpeded. When we are oblivious to the rhythmic (temporal) nature of experience-the integration-disruption-reintegration cycle, starting with a qualitative whole, whereby the equilibrium of a given situation is followed by a disruption that transforms the unified situation into a problematic one, and, finally, the attempt through inquiry (reflection) to establish a new equilibrium, a new unified situation, a new qualitative wholeness-our experience becomes stunted, and it soon dies; growth stops. A pervasive meaninglessness takes over.

Let me provide an example to illustrate what Dewey has in mind by the phrase "rhythm of experience" and the role of reflection in the marking of experience as an experience. As humans, we all seek to maintain a state of well-being, where we go about our daily habitual lives without unduly exerting ourselves at every second to question and inquire into every aspect of our existence. There is no need to do that. We find ourselves in an enveloping undefined whole that we do not consciously analyze and verbalize all the time. Sooner or later, for one reason or another, however, the state of well-being is disrupted, since we are not isolated beings immune to changes occurring in our physical and social environment. Things happen, sometimes quite dramatic things, as in the following situation, and then we are compelled to inquire and reflect upon what has gone wrong:

Take Miguel, for instance. He feels content. His life makes sense. He is happily married. He has a secure job that pays the mortgage and supports his children's schooling. He has a home he returns to happily every evening. He loves his wife. He has his buddies he hangs out with every once in a while. Physically, he's in okay shape. He has plans for the summer. Life is good. He is content. His sense of what his life is all about and where he is headed to is settled. Then, something drastic happens. One morning, his wife, the mother of his children and the person he has shared sixteen years of his life with, breaks the news that she is a lesbian and that she is going to leave him for Tracy. This would likely create a dramatic tensive disruption in his experience. The overall quality of contentment, the equilibrium he has been enjoying with all the values and understandings that constitute it, is 
inevitably disrupted. The situation, with its taken-for-granted meanings and values, no longer makes sense and becomes problematic. A deluge of overwhelming questions overtakes his entire being: "I have been married to a gay person all this time. What does that tell me about who I am? What is the meaning of all this? How will this impact my life? My children's lives? What is the meaning of my marriage? Why was I attracted to a gay person in the first place? Am I gay as well? This is not making any sense. What am I going to do? How am I going to explain all of this to the kids? How will they react?"

A new understanding, a new perspective, a novel take on things is called for. Now, how are we supposed to respond to such a situation, in which our whole world turns upside down and the old way of doing things, our old habits, no longer are helpful in understanding the new situation? Our cherished values and the things we have taken for granted for so long are being challenged. Our very identity is at stake here. How are we to respond?

Well, we reflect. We take a step back and reflect on the situation, and not for the sheer fun of it. We are compelled to reflect, and we reflect in ways that attempt to restore the equilibrium, to return the state of well-being to our lives again so that the world makes sense again and we feel we are part of it in an integral way. However, the old equilibrium is gone and it is not coming back. A new equilibrium has to emerge, one that is more in line with the transformed situation. (There are other options available, of course. The new situation can be so overwhelming that we simply unravel mentally, in which case we might, for example, take our own life. Obviously, such an option does not help us to re-establish a new equilibrium. Rather, it completely eliminates the possibility of growth).

More often than not, this requires (especially when the crisis of meaning is that extreme) some sort of transformation in the way we understand the world. We revise our old ways and are compelled to change our perspective, our interpretation of the facts. We re-evaluate our values. We start questioning things. In short, we start thinking, which is by no means an algorithmic process. Thinking, as Dewey understands it, is a whole body-mind-environment process. It is not merely going through a checklist. It is not merely following a pre-determined protocol or procedure: "Do this first and do this next if and when your wife reveals that she is gay and walks away with Tracy!"

Thinking, in the Deweyan sense, is not easy and requires a lot of effort on our part, and not just mental effort but a coordinated effort of our entire being. But at the end, if we can make it, we will establish a new equilibrium, a better one, a more encompassing, a more caring, a more understanding, a more flexible, a more open-minded equilibrium. In other words, we will grow. We will grow out of the limitations of our previous understanding of the situation into a new understanding where, after being plunged into despair, with no satisfaction in the world but only puzzlement and frustration, a fresh standpoint is adopted that restores the 


\section{Sevket Benhur Oral}

sense of being "at home in the world." 20 That fresh standpoint might be one where Miguel feels a deep appreciation for the humanness of his partner, her courage in being true to herself. He now can make sense of what his relationship to his wife has been all about. The parts constituting the once-disunifying experience compose themselves into a unity. The temporal unfolding has been positively dreadful, and yet the parts come together and a transformation of the self takes place as Miguel settles into a more expanded sense of his self and world.

When a new equilibrium is finally reached, when the sense of being at home in the world is restored, the unique episode we have undergone becomes an experience. We can look back and say, "Gosh, that was an experience." We realize that we have grown through the process, one that has reached a point of consummation rather than a mere cessation.

As has been argued in the section on consummatory experience, the unimpeded, continuous flow of the rhythm of experience is an antidote to a perceived sense of meaninglessness and helplessness, and, therefore, that it makes truly educative experience possible. In other words, only meaningful experience (consummatory experience) can become a site for growth, that is, a site for a more meaningful experience to unfold for oneself as well as lead to a meaningful experience (educative experience) in others. In a more formulaic manner, it can be stated that when experience is meaningful (albeit sometimes painful), it then becomes educative. The dialectical relationship between the consummatory experience of teaching and the educative classroom experience leads to growth (as enhanced experience of meaning) in the teacher(s) as well as the students, for it is a single reciprocal process.

Since the focus of this paper is the consummatory experience of teaching, that is, what makes the experience of teaching meaningful from the teacher's perspective, this dialectical relationship will now be explored in relation to the process of being and becoming a teacher. That is, by inquiring more closely (in a phenomenological vein) into what it means to be a teacher and how one becomes a teacher, we will gain insight into the dialectical relationship between the consummatory experience of teaching and the educative classroom experience from the teaching side of things.

\section{Being and Becoming a Teacher}

What does it mean to be a teacher and how does one become a teacher? In other words, how does one experience being a teacher and how does this experience grow, and hence lead to educative experience in one's students?

In a very general sense, being a teacher is about being in a classroom ${ }^{21}$ just like being a doctor is about being in a hospital, or being a lawyer is about being in a courthouse, or being a pilot is about being in a cockpit of an airplane. In an everyday understanding, it does not make sense to imagine a doctor without a hospital, or a lawyer without a courthouse, or a pilot without a plane. They usually go together. At least, we expect them to go together. Similarly, a public school teacher 
without a classroom does not make sense. Being a teacher, in other words, is essentially about being in a classroom, that is, experiencing the classroom situation in a meaningful unified way. The unitary experience of being a teacher in a classroom merits further elaboration since it is the task of this section to clarify the difference between the situational unity of experience in general and its consummatory, that is, most fulfilling mode.

When you are a teacher, you get up early in the morning and go to school, for instance. Why do you get up so early in the morning and go to school? Well, because you are a teacher and that's what teachers do. They are expected to get up early in the morning and go to school. Yes, but why? Well, simply put, because it is their world; it is the world of a teacher and you are in this world, and this world is experienced in a meaningful way. Getting up early in the morning and going to school is the sensible thing to do. It is what makes sense. Just like the life of a farmer who gets up even earlier and immediately starts doing the chores makes sense in the world of a farmer, the life of a teacher makes sense in the world of a teacher.

Where does this meaning come from? You do not every time you get up early in the morning deliberately assign meaning to this world in an external way as if the world and you were two separate distinct things. You are compelled to get up early in the morning and go to school not because you think about it, deliberate, and finally decide to go to school. Rather, you just do it without reflecting on it because you find yourself in a situation that already makes sense. You are part of a larger unified whole that makes sense.

You have a classroom you are in charge of. You have a subject matter you are responsible for. You have students you care about. You have colleagues you need to consult with. The world of a teacher you meaningfully inhabit is neither just a world of your imagination, something you have created in your mind, nor something that is totally external and independent of you. It is neither an internal private world nor a strange external world. Rather, you are already outside of yourself absorbed in and committed to myriad activities that as a whole make sense. You are a teacher.

When you are a teacher, you are already absorbed in the world of a teacher. Being a teacher means being already absorbed in the life of a teacher. You are unreflectively absorbed in the everyday life of a teacher. Unless you are going through a crisis of meaning (as in the case of Miguel), you do not generally ask why you get up so early in the morning and go to school. It does not even occur to you to ask such a "silly" question. The reason is that there is no need to ask such a question because the world of being a teacher already makes sense to you. It is a unified field experience and you are already given to it. You are already committed to it.

For Dewey, the world of a teacher consists of living in a series of interlocking situations. These situations are qualitative wholes. That is, they are qualitatively experienced. There is a certain quality to getting up early in the morning. If you are not a morning person, the experience of getting up early in the morning is not 


\section{Sevket Benhur Oral}

undergone in enjoyment. Rather, it is quite torturous. You complain and moan about it. In contrast, if you are a morning person, the experience is refreshing. Not only that, you might also feel more productive in the morning and therefore get most of the preparations for your classes done in the early morning hours before you even get to school. As you wake up early in the morning and get ready for school, you anticipate what you will be doing in your classes, what kind of materials you will need, how you are going to review the things you did the previous day, how you are going to expand on the lessons covered previously, how you are going to deal with Ryan, who happens to have concentration problems, how you will relate today's topic to what you have so far discussed, and so forth.

As a teacher, you anticipate all these and many more situations, each of which is imbued with a certain overall quality and linked together in a temporal unfolding. Through such anticipation, you psychologically prepare yourself for the day ahead, trying to foresee some of the possible problems, and also think of possible ways to resolve them, even before they arise. In other words, you find yourself already engaged with the meaning of the events of the recent and remote past as well as the imminent and far-off future-the "from which" and "to which" of the transactional situation. There is a certain direction and orientation in time. You are extended backwards and forwards in time; and you do this without even thinking about it.

Once you get to school, you realize that you know your way around. You know how to orient yourself in the school environment. Once again, there is a certain pervasive quality to your experience of the place. You know the place, and not just the physical layout but what every single room feels like. Perhaps this morning there is an overall welcoming atmosphere. There is a palpable excitement in the air and you are in a good mood as well. Last night the school's basketball team had a victory in the semi-finals. Your throat is still sore from all that dedicated cheering. Also you are excited about the activities you have planned for your freshman English class. You are going to have them debate the pros and cons of human cloning. You feel good to be here. There is a certain upbeat quality to it. The familiarity with your environment makes you feel at home. After getting your coffee in the teachers' lounge, you are headed to your classroom, greeting people on your way with a generous smile. The quality that runs through every single encounter, every single interaction with the physical and social environment, with the objects and the people, is experienced with a certain significance. The qualitative experience of the place gives meaning to each interaction and binds them together. ${ }^{22}$ Everything makes sense. You are absorbed in the world of being a teacher.

Your morning group is composed of students of a staggering range of abilities, socioeconomic levels, and ethnic backgrounds. You teach freshman English and sophomore social studies. Gary, one of the students in your freshman English class, comes from a single-parent home. He, his mother, and four siblings live in a three-room apartment. The family is on welfare. It is difficult to get him to respond 
to anything. You really do not know how to handle the situation. Your interaction with him is pervaded by uncertainty and uneasiness. Jessica is a bright student who is responsive in class. She is the daughter of a professor of chemistry at the state university. She is intellectually advanced for her age. She is very creative with her writing and receptive to your unconventional ways of getting students to think outside the box. She likes you and you can see that in her eyes. A certain sense of ease and spontaneity runs through your interaction with her.

The pre-reflective absorption in the world of being a teacher, the temporally unfolding series of qualitatively experienced situational wholes, entails that you as a teacher already have a certain understanding of who you are as a teacher, who your students are, where they come from, what their needs are, what each individual's strengths and weaknesses are, and what you think you should do to reach out to them, how to present the subject matter, how to modify it based on their interests and backgrounds, and so forth. Whether you entered this profession out of dedication for this is the profession - or rather, vocation - in which you find your greatest fulfillment, or out of desperation because your anxious parents were concerned that you get a teaching certificate as an insurance policy against future unemployment, ${ }^{23}$ you find yourself in a situation, that is, you always already experience the world of being a teacher in a meaningful way colored with a certain quality. Being a teacher is therefore being in the world of a teacher. This world is situational, experienced qualitatively, and it unfolds in time. In short, it is dramatic in the sense that every situation has a peculiar gravity to it. Furthermore, you are given to it; it is not something you entirely control.

If this is the case, that is, if the world of a teacher is already experienced in a unified way, whereby a pre-reflective absorption in an undefined qualitative whole envelops the humdrum course of daily activities, how then does this situation lend itself to be experienced in a consummatory way? To illustrate how, let me provide a rich description of an experience in a classroom situation. Examples of consummatory experiences in the context of art are somewhat easier to describe. Performances that have a narrative structure that provides unity to the whole experience, that leads to enduring changes in both the experiencer and the experienced; a transformation of the experiencer and the meaning of the experienced; the parts of the experience unfolding harmoniously colored with a unifying emotional state ${ }^{24}$ are relatively easy to spot when we are discussing experience in relation to art objects or performances.

For instance, in my case, seeing Riverdance (the phenomenal Irish show) in the Stephen's Auditorium at Iowa State University, and my first Cirque du Soleil show in the Royal Albert Hall in London, definitely count as consummatory experiences and it is fairly straightforward to illustrate why they do so. Riverdance: a tribute to the Irish spirit. That night I left the auditorium enamored with the Irish spirit. It was such an (overpowering) experience that I was delighted, almost euphoric, to 
have witnessed such beauty and harmony. It wasn't just a deep appreciation of the Irish cultural achievement. I felt reassured of the goodness of human nature and its accomplishments. The spectacle has engendered an enduring affinity with the Irish and through them the goodness and beauty humans are capable of. Similarly, Varekai, the Cirque du Soleil show I enjoyed at the Royal Albert Hall, was an experience. What an experience indeed! Another tribute to the human spirit, extending my conception of artistic creativity and what humans are capable of with their bodies.

An educational experience, however, is slightly more challenging to describe, but I'll have a go at it. Below you will find a thick description of a classroom situation, which, I contend, constitutes an educative experience for the students and a consummatory experience for the instructor. Again, the same rhythmic (temporal) nature of experience-the integration-disruption-reintegration cycle-is in action:

I truly enjoy teaching "CI 204: Social Foundations of American Public Education," an educational foundations course for teacher education students. I feel passionate about it. There is a certain sense of feeling at home in what I am doing when I am in class with my fellow students. I have this feeling that there is indeed a possibility to actually create an environment where we can make a difference in each other's lives for the better, where we can grow together. I am not naive about my own powers, though, or those of my students; I am aware of the limits of my personal commitment and what I can hope to achieve within the limits of the institutional structure of the university where I work. Nevertheless, while I am teaching I feel fully alive. I feel present to myself and to my environment. It is a revitalizing feeling. As Dewey says, "the demand of the soul for joy, or freshness of experience" ${ }^{25}$ is somehow met when I find myself engaged with the ways of this course.

The course has a flexible structure. It allows room for being spontaneous. Not everything is set in stone. Things are subject to change, though not all the time. There is an element of stability as well as precariousness. I try to strike a balance between the definite elements that provide a core structure and direction to the course and some level of indefiniteness that provides room for experimentation, novelty and spontaneity. The content revolves around certain major themes, some fundamental big ideas such as "the human condition," "modernity," "being fully human," "the relation of plurality and unity" and that "things are really interconnected." There is a certain element of movement to the whole course. And it is not linear, step-bystep, from simple to complex. The movement is more dynamic. It is a flow but there is no flow chart that can exhaustively represent it, for it is not entirely uniform and predictable. Rather, it is constituted by various elements in tension with each other. Moreover, there is not an easy resolution of the tensions that are experienced because the students themselves become the elements of the situation. They become part of the flow. Things are not merely external to them. They are not merely learning about some subject matter (a bunch of factual information about U.S. educational 
history) from a distance. They are learning about themselves. There are no "learning objectives" that are pre-specified, like one puts together a grocery shopping list. The objective is to be engaged and it is not something that can be achieved at the end.

Moreover, it is not merely a mental engagement. The focus is not on intellectual analysis of certain given concepts (given by me that is, or given by the curriculum I am supposed to transmit). Rather, the focus is on engagement with meaning and values, and I do not give these to my students, for I do not possess them like I possess coins in my pocket; rather, they are in the situation. Meaning and value reside in the situation, if we are really seeking a "location" for them. ${ }^{26}$ They belong to the situation. They are not in my mind to be transferred to the minds of my students for we are not self-enclosed subjects, aware of only our own mental states essentially disconnected from the others and the situation at hand. ${ }^{27}$ The ideal is not complete detachment from what is at hand, which is not possible anyway. Meaning and values are not objectified to be studied as if they were entries in an encyclopedia; rather, they are embodied. That is, the focus is on how we live the meaning and values we cherish, how they orient us, how they shape and mold us, how they determine us and how they free us. It is about how we seek and maintain a state of well-being, how we establish a coherent account of things, and when such an account is inevitably disrupted, how we respond to this disruption and try to form a new and a better, more encompassing account. In other words, it is about the transformation of meaning, which always takes place within a situation. There is no situation-free transformation, or to put it somewhat differently, we do not transform to a situation-free experience of things. We always remain in the situation. Yet our understanding of the situation is enriched through transformations of meaning. This, I believe, is what Dewey means by consummatory experience, that is, growth.

Transformation of meaning is not exclusively a mental process. It is situational. It involves the whole human being as an integrated body-mind-environment. It is not simply an academic affair. More importantly, it is a social, moral, emotional, cultural, and spiritual affair. As was mentioned before, although the aim cannot be complete detachment from the situation at hand so as to achieve a purely cognitive relation to the subject matter, the capacity to take a step back and momentarily suspend any judgment on the topic at hand by temporarily detaching ourselves from the taken-for-granted understandings of the world and our place in it is essential. In other words, reflection is essential. As long as it is appropriately and intelligently contextualized, that is, with the larger multi-dimensional picture in mind (the situational character of experience), taking a step back from our customary ways of understanding the world is indispensable for true intelligent thinking. ${ }^{28}$ True thinking, as opposed to mere cognitive activity, is an act that gives us the opportunity to shift our attention from what is considered to be the way things naturally are to the perspective of the other-what is not natural, 
what is not conventional, what is not taken-for-granted, that is, the alternative, the bizarre and different, in short, the possible.

I would like to remark that the very encounter between my students and I itself constitutes an occasion for thinking. Imagine an instructor from Turkey (the country!) who is not a native speaker of English teaching the social and philosophical foundations of the American public education in Ames, Iowa-hardly the first place that comes to mind when we think of the possibilities of diverse encounters, despite what has been happening in rural towns such as Postville, Iowa, where a group of Hasidic Jews of the Lubavitch movement from New York, immigrant laborers from Mexico, and the rural Protestant Iowans, predominantly of German and Norwegian descent, find themselves in a maelstrom of bizarre encounters! ${ }^{29}$

At this point, let me dwell a little bit on how I conduct the course given that the encounter between a Turk and the U.S. Midwesterners has already taken place. In the beginning of the course, I point out that "CI 204: Social Foundations of American Public Education" is essentially a humanities course, that is, a course where we focus first and foremost on the human aspect of the process of teaching and learning. Since, as humans, we are studying ourselves, I go on to say, this course is a little different in content and style from the so-called physical/hard/ natural sciences, where the object of study essentially belongs to nature, that is, it is either physical-chemical or biological in nature and cannot therefore directly communicate with us using human language. Human beings are not only physical and biological organisms, they are also, and, perhaps more importantly, social beings capable of forming unique and evolving cultural communities and so, I point out, in understanding the human aspect of the process of teaching and learning, our attention will be drawn primarily to the social and cultural dimensions.

By this move I intend to acknowledge and highlight (at least to myself) the distinction between the social and human sciences (Geisteswissenschaften) on the one hand, and the natural sciences (Naturwissenschaften) on the other. It is more often than not the case that my students do not have the slightest idea why they should be interested in the significance of such a distinction. Yet I have confidence that as the semester progresses this is bound to change. At this point, the majority of them could not care less about "the idealistic echo implied in the idea of Geist ('spirit') and of a science of Geist." 30 They do not realize that it is exceedingly important to acknowledge that the human sciences have their own logic starkly distinct from that of the natural sciences. They do not suspect that their instructor is a staunch admirer of John Dewey and takes very seriously his philosophical project, for which the distinction is crucial.

The course is basically about the history of American public schooling. To that extent it has a well-defined focus and can be treated fairly formally using a well-established textbook. However, my intention is not to stuff my students with information regarding a series of historical events presented chronologically. 
Rather, I aim initially to provide a context, a non-offensive base that everybody, irrespective of where they are from, could relate to. My aim is to emphasize first what is common to all human beings before tackling the troubling issue of what separates us, that is, the inherent plurality of perspectives: irreducible differences and diversity. By that I intend to convey the message that this course is not just a typical 3-credit college course that needs to be taken to fulfill some requirement for their terminal teaching degree, but is rather about all of us and the social and historical meaning of the period that we all inhabit now, that is, modernity. We are all modern human beings. I therefore start out with a rich description of the so-called "human condition" (in modernity) that I believe reflects a common experience everybody can sympathize with. At this point, they are mesmerized but they cannot exactly tell why.

Before we look at the description of the concept itself, however, let's take a pause here and examine briefly how I intend to make the concept function in the classroom situation. The concept "human condition" is not merely a bit of information on which the students will be tested later. Rather, it is reflective of the very situation we all find ourselves in. Our situation is permeated by the human condition. In this sense, the concept "human condition" is continuous with that which it refers to. The need to name, delimit, and articulate such a concept arises from the situation itself and, as a concept, it brings out some aspect of the situation into prominence and then returns to the situation enriching our understanding of it. The concept shifts our attention to something that we always already tacitly experience but have not perhaps explicitly noticed before (the enveloping undefined qualitatively experienced whole). It does not however exhaustively represent the situation, for it cannot exhaust the situation. The concept is not meant to replace the situation. At no time does it have an independent existence as an idea hovering above, antecedent to the situation or disconnected from it. It remains within the situation. It makes sense, is meaningful, to the extent that it emerges from and refers back to the situation, and by situation I basically refer to the multi-dimensional matrix of relations between the teacher and students and not just the physical layout of the classroom, which, in our case, has a rather traditional formal structure, with the teacher facing the classroom poised to present a particular subject matter to a group of students. The goal is not to learn the concept "human condition." The goal is to learn about the human condition itself, that is, our very condition that we find ourselves in at that particular moment by engaging with/in the situation. This engagement is essentially an interchange between the teacher and the students and does not have a simple location. Teaching and learning take place in the situation and not within the teacher or the students in an isolated atomistic fashion.

Now, let's return to the description of the concept of the human condition itself. What is the human condition that I claim we all share regardless of who we are and where we are from? From a philosophical perspective, what I mean by this 
phrase is that we are already in the world! To my students, and probably to most readers as well, this is a "duh!" moment. It usually sounds quite obvious and insignificant, even trite. However, I know that this is a reference I am making to the German philosopher Heidegger's neologism "being-in-the-world" and concomitant with it the way he explicates the structure of care as the human condition. I also know that what Heidegger calls care is anything but obvious! Most likely, this is a connection that only I am aware of. My students have probably not even heard of the name Heidegger, let alone being familiar with his philosophy, and therefore would not be able to make a similar connection themselves. To that extent there is a certain mismatch, a non-coincidence, a tension, if you will, between my understanding and theirs. At this point, an understanding of Heidegger's philosophy is something that only I bring into the situation.

I do not mention Heidegger to them, however. It is not necessary to discuss the idea of being already in the world in reference to Heidegger's work (although it is possible). For they already are in the world, and as soon as they hear this phrase what usually happens is that their attention shifts to this obvious fact, so obvious that it has totally eluded them all this time. They now become aware of its obviousness, which they used to take for granted without noticing it. The information, if you will, that we are already in the world is not something we are constantly aware of in our dealings with things. We needn't be. That knowledge, however, is somehow present in the situation. (If you think about it, we really are already in the world, that is, way before we cogitate about our existence, we simply exist). It is assumed, and not in the sense of a deliberate thinking process whereby we ponder intently the big questions. It is simply experienced. It is there. It is had. We are already in the world! It is somewhat in the background and whatever we are engaged with is made possible by the workings of this information in the background. That you are already in the world makes it possible for you to read that you are already in the world! Totally bizarre, huh? Well, that sums up the overall reaction of most of my students.

It is essential to notice that the knowledge that we are already in the world is not cognitive in nature. It is not explicit information that we painstakingly process. It is more like a quality that has us, an overall quality within which we are enwrapped. It discloses itself as a pervasive mood. (Think of the mood you are in right this very moment as you are reading these lines. Your mood is not just your emotions. Rather, it is constituted by all the things you have brought with yourself into the reading of this, in short, your very subjectivity.) For instance, we can be indifferent, bored, apathetic, depressed, downtrodden, anxious, nervous, irritated, joyful, full of anticipation, excited, enchanted, carefree, energetic, easygoing, encouraged, hopeful, angry, bitter, upset, enamored, detached, cool, and so forth. We are already in the world and we know, or rather, experience that through the mood we find ourselves in. We come to class with certain expectations, fears, hopes, 
plans, strategies, attitudes, habits. Maybe, as a freshman, I might be a little anxious. I do not know what to expect. I am also curious about this new class; I am eager to meet the new instructor. His name is strangely familiar! Ben-Hur! I remember the movie. I might even be excited about the prospect of learning new things. Or, maybe, I am just bored and have no expectations whatsoever for this class. After all, I am forced to take this class by my advisor this semester-the sooner you take care of it the better, she says-and it is just one of those college courses I need to take to fulfill some requirement to get my degree, which probably is not directly relevant to what makes my life fulfilling and meaningful so I just have to deal with it. Either way the mood we are in, the quality that pervades the mood-the adjective, if you will-defines the way we are in the world and what we bring into the situation. And it is not something we think about; we simply experience it, or rather, we are enveloped in this experience.

This experience, however, is not insignificant. It is not merely there. On the contrary, it is an organized, active, structured lived experience and has a crucial function. It connects us to the world that surrounds us. It unifies us with our environment. We participate in the world as part of a "field interaction." ${ }^{31}$ This interaction is initially, and for the most part, pre-reflective, pre-analytic but no less informative. It informs us deeply regarding the world we live in. It forms our immediate understanding of the world that surrounds us, and not just the physical world, but also and more importantly the social world. It gives us the world and us to the world. It is not "information," as the latter is understood in the sciences of cognition. It is pre-cognitive.

Moreover, it is a dynamic activity constitutive of the field of our possibilities. It predisposes us in certain ways and not others in the sense of how we are going to orient ourselves, how we are going to relate to our physical and social environment, how we are going to understand ourselves in relation to our physical and social environment. What we are going to receive from our social and physical environment, how we are going to respond to the things around us, what we are going to do and how, what we are going to undergo and how, what we are going to perceive, what we are going to pay attention to are all fore-determined by virtue of inhabiting (experiencing) a qualitatively pervaded situation, by being in a mood, that is. And let's remember that it is inevitable to be in a mood. Moodlessness is out of the question.

So when I say that it is my central role as a teacher to be open to the field of my students' (and my own) possibilities, that is, having an understanding of the situation, I essentially talk about that ability to attune to the qualitative nature of the situation we all reciprocally constitute, that is, the ability to sense the moodto feel the interplay of the qualities that go into the make-up of the situation. It is not a very helpful strategy to memorize the entire "Encyclopaedia Britannica" in order to have an understanding of a given situation. Having an understanding has 
not so much to do with information and our cognitive ability to process and retain it. It has more to do with a sense of being in touch with things, a sense of being at home with things no matter how bizarre they might initially appear, a sense of how to relate to things, a sense of the possibilities of things, a sense of being in touch with the qualities inherent in a situation, a sense of how the continuities as well as disruptions unfold and are interconnected.

This whole thing about being already in the world puzzles my students a tiny bit, in some cases, quite a bit, and it is exactly what I intend to do by focusing on a taken-for-granted aspect of our situation, a fundamental aspect in this case. An opportunity to have a fresh look at the situation is brought into being. A disruption has taken place. This is an educative moment for all of us. What I hope to accomplish by this move is to bring into relief the possibility of opening up an entirely new dimension to our existing situation as we inhabit (understand) it. To use a more colloquial phrase, it is a wake-up call. To put it more paradoxically, we go beyond a given situation yet we remain within it. Or we can say that a new dimension is added to our present understanding of the situation. This is revealing to the extent that there is continuity between the prior state of understanding, where we take things for granted, and the realization of this new dimension, this novel way of understanding things. It is educative to the extent that the prior and the novel are seen to be two different phases of the same movement, or two different moods, two different senses.

When it is understood that a transformation has taken place, that what we knew before and what we now know are intimately connected with each other, are reciprocally bound to each other, are mutually conditioned, and that there is a certain order and logic to this unfolding movement, that it is not entirely haphazard, then this transformation is meaningful. Moreover, it is refreshing, intriguing, enlightening, rejuvenating, revitalizing, animating, or puzzling, confusing, annoying, disconcerting, disquieting, baffling, unsettling. In either case, it is anything but deadening, numbing, enervating. That is, it is anything but anaesthetic! It is aesthetic. I take this to be the meaning of Dewey's conception of "consummatory experience" being aesthetic.

The disruption that has taken place and the ensuing struggle to make sense of it propels me and my students to reflect on the taken-for-granted meaning of the situation and inquire into the possibility of new dimensions within the situation. My students and I engage with the problematic/disruptive situation pregnant with possibilities. Having inquired into such possibilities together, the earlier confusion leads to a more refined understanding of the existing situation. This, however, is not merely an accumulation of knowledge on the part of the students. They have not learned anything new in the traditional sense. Rather, they engaged with the concept not as an information segment that they need to code and store but as something that touches them and forces them to think about themselves. 
They did not leave their selves and how they relate to the world around them untouched. They have acquired a new perspective, one that is more encompassing than the prior one. As Dewey puts it, they were "introduced into a world beyond this world which is nevertheless the deeper reality of the world in which we live in our ordinary experiences." ${ }^{2}$ By having undergone such an experience, they emerge changed. They now assume a perspective that was dormant in their pre-reflective absorption. This perspective is not simply one among other possible perspectives. It is a more refined and expansive perspective, for the new perspective afforded them the ability to become aware of the "enveloping undefined whole." Now it is defined.

Once my students go through this "bizarre" experience, once they become aware of the enveloping undefined whole, once they feel alive, I share several examples from my own life with my students and ask them to share theirs to illustrate the complexities of the human condition in modernity and bring home the message that the world we find ourselves in is characterized by both stability, familiarity, peace and quiet as well as indefiniteness, ambiguity, confusion, anxiety, unknown and uncertain conditions. I can see in their eyes that they are able to relate to what I am talking about. This is very gratifying. On the one hand, the things we discuss are extremely abstract (the human condition). On the other, they are very real and concrete. Going through the rhythm of experience together in this fashion leads to educative experience in my students and is consummatory for me. The two are not separable.

Consummatory teaching experience, then, is about experiencing the world of being a teacher in a heightened sense of situated meaning. As has been shown before, for Dewey, experience is a meaningful qualitatively experienced situational whole. Consummatory experience is a heightened sense of the meaning of this whole, which can be qualitatively positive or negative. Your sense of being a teacher can be experienced in a very fulfilling gratifying manner, or it can be experienced as a heavy, strangulating, suffocating, unbearable experience. In either case, it is consummatory. Consummation, despite its connotations, should not be equated with completion, an end state, a happy ending, so to speak. Rather, it simply indicates a state of heightened meaning that opens up the possibility of further growth. When we experience such a state, when our experience is consummatory, we gain a keen and discerning understanding of the meaning of the situation we find ourselves in, and based on this understanding we act in such a way that, having learned something vital about ourselves and our relationship with the world we inhabit, we restore the integrated state of being with the world. Such integration, however, is not a timeless perfection, whereby a state of bliss overcomes us and all conflicts and tensions melt away. On the contrary, when our experience is consummatory, a dynamic state ridden with tensions unfolding in a dramatic way is realized.

In other words, we acknowledge the gravity of the situation-its limitations and possibilities_-and respond to it in the most appropriate way at a given particular 


\section{Sevket Benhur Oral}

moment. Acknowledging the gravity of the situation, that is, seizing the meaning of the dramatic unfolding of events in time, is not solely a pristine cognitive process for we are not detached observers outside of time, outside the flow of events. Rather we are in time; we are flowing in time. We do not see everything at once in a timeless fashion. Some of the elements comprising the events are obscure. The meaning of the events is not clearly disclosed once and for all. We do not have a perfect understanding of the situation at any given time. The picture is always whole but incomplete. Like a pebble thrown into a still pond creating ever-growing waves, each ripple is a whole but at the same time it is constantly expanding and growing thicker. It is the movement, and the ability to move and be moved within it, that is consummatory. Consummation does not mean a perfect, eternal, timeless understanding of the meaning of the situation. Consummation is not a timeless, complete apprehension of meaning. Rather, it is a heightened sense of the lived meaning, of the movement of life. The movement of life-the cognitive moment, if you will-cannot be captured in isolation; it cannot exist apart from our ability to move (the experience of doing, that is, action) and our ability to be moved (the experience of being affected, that is, emotion).

\section{CONCLUSION}

It is my conviction that a solid teacher education program requires first and foremost a unifying principle-a clear unifying vision of what good teaching means. Deweyan consummatory experience provides such a vision. Teaching as consummatory experience is what good teaching is all about. For a teacher education program, teaching as consummatory experience not only provides a unifying principle that permeates all coursework and clinical experiences, it also embodies a principle of unity because consummatory experience is unified experience where theory and practice are integrated. The goal of teacher education is unified experience for teachers. This means that coursework and clinical work should not be divorced from each other. Theory and practice are to be integrated.

Tightly interwoven clinical and coursework is a first step in increasing the likelihood of creating learning situations where consummatory experience of learning to teach might unfold:

We learned a lot in university classes, but I think that that which we really needed to know, we did not get. I think that a lot has to do with the "here and now." It is easy to think of, "Well somebody does this to me, then I follow this and this and this." But every situation is so different and every student is so different. So what I learned in the abstract does not seem to fit any particular case. ${ }^{33}$

Whether pre-service or in-service, novice or seasoned, what all teachers really need to know cannot be taught but can be learned. This is the consummatory 
experience of being and becoming a teacher in a classroom. As I have tried to explicate here, this experience is not merely a matter of cognition. In other words, it is not about knowing per se. Therefore, the sense of panic experienced in any discussion of knowledge needed for teaching is misplaced. Teaching and learning to teach, when approached with an aggressive, objectifying attitude, appear to be immensely complex and demanding tasks to teacher educators. When teacher educators waltz with the illusion that the best way to get knowledge of things is to objectify them, that is, when we grasp things not as events with significance unfolding in a multifaceted dynamic situation to which we belong but as things looked at by an outside observer disconnected from their environment, we "de-live" them. ${ }^{34}$

When the consummatory experience of being and becoming a teacher in a classroom is "de-lived," all of a sudden, we remove ourselves from the temporally unfolding situation we are immersed in and delude ourselves into thinking that we can "rise above our environment to some pure, lofty pedestal and pass judgment on the world, as if we were untainted by it." ${ }^{35}$ Moreover, we sincerely believe that the distance gained will engender clarity and a firm grip on the situation. What it engenders instead is distortion. The living situation, when "de-lived," becomes distorted. Instead of living in tune with the significance of the situation we are immersed in, we frantically attempt to control it from outside. We do this by analyzing, or rather, compartmentalizing the situation we have objectified into manageable bits and pieces. The situation then looks incredibly complex. We become overwhelmed with all the elements that need to be accounted for and controlled. We literally become control freaks! We freak out because we have isolated ourselves from the situation at hand, but at the same time we need to get a grip on the situation as well. This is an impossible situation: trying to be in and out at the same time!

For Dewey, this conception of knowing - the quest for certainty as he calls it - is at best ill-conceived, at worst seriously pathological. For him, the situation is never atomistically constructed; rather, it is always already holistically given and us within it. It is not composed of separate and independent elements that need to be combined through the agency of a misconceived Cartesian cogito. As teachers, we are not "calm, antiseptic observer[s] dressed in a white coat, standing on a lofty tower and describing everything neutrally." ${ }^{36}$ We are never isolated creatures, but instead vulnerable human beings immersed in a specific environment made up of other live things and humans that are equally vulnerable. We are situational creatures through and through, and the enfolded meaning within the situation dramatically unfolds, and we unfold with it. We are not out there on our own seeking to know, control, and manage the world we are not a part of. We are in the world in association with other people in it. It is a shared world. We share it with our students and colleagues and others. We do not have to know everything; we do not have to control everything; we do not have to be on top of everything. We do not have to be an expert. We can rely on others. It is okay. We can rely on their judgment. We 
can trust them. We can ask for help. Other people, including our students, know a thing or two as well. We need to relax a little bit. We are not running the show by ourselves. It is not a one wo(man) show in the first place.

Besides, the students are not merely there to be known about so that they can be controlled and managed. They are fellow human beings just like us. They are as alive as us (if they are not already anesthetized through years of mindless schooling). They are as a part of the situation as we are. We can rely on their judgment, understanding and perceptions. They will tell us what we need to know and what we need to do, not necessarily verbally and explicitly, so we have to be mindful of the situation and be able to feel what is going on. When we encounter them, we are also encountered. When we experience them, we are also experienced. The relationship is reciprocal. It is not one way. It is not a matter of us controlling them. People and things respond to us as much as we respond to them; they let us know who they are and how they are.

The consummatory experience of being and becoming a teacher in a classroom, therefore, is not as complex and solitary a process as it might appear to the eyes of a theoretically inclined university researcher who has made knowing what is going on in a classroom (analyzing every bit of it) her life's work. It is rather quite simple, immediate and enjoyable as a matter of fact once we stop trying to know everything-once we relax the impulse for control_for being and becoming a teacher is not something to be known, it simply is to be had. It is an existential condition. That is, it is situational. It is not theoretical. It needs to be lived in the here and now with this group of students in this classroom at this time. It can only be experienced in the concrete in the presence of others.

\section{BiBLIOGRAPHY}

Alexander, Thomas M. John Dewey's Theory of Art, Experience, and Nature: The Horizons of Feeling. Albany: State University of New York Press, 1980.

Bloom, Stephen G. Postville: A Clash of Cultures in Heartland America. New York: Harcourt, 2000.

Dewey, John. Art as Experience. Vol. 10 of John Dewey: The Later Works, 1925-1953, edited by Jo Ann Boydston. Carbondale: Southern Illinois University Press, 1987.

- - - "Art in Education - and Education in Art." In John Dewey: The Later Works, 1925-1953, edited by Jo Ann Boydston, 2:111-15. Carbondale: Southern Illinois University Press, 1984.

-_- Democracy and Education. Vol. 9 of John Dewey: The Middle Works, 18991924, edited by Jo Ann Boydston. Carbondale: Southern Illinois University Press, 1980.

-__. "Qualitative Thought." In John Dewey: The Later Works, 1925-1953, edited by Jo Ann Boydston, 5:243-62. Carbondale: Southern Illinois University Press, 1984. 
Gadamer, Hans-Georg. Truth and Method, translated by J. Weinsheimer and D. G. Marshall. New York: Continuum, 2003.

Gallagher, Shaun. Hermeneutics and Education. Albany: State University of New York Press, 1992.

Harman, Graham. Heidegger Explained: From Phenomenon to Thing. Chicago: Open Court, 2007

Inwood, Michael. Heidegger: A Very Short Introduction. Oxford: Oxford University Press, 1997.

Jackson, Philip W. John Dewey and the Lessons of Art. New Haven, CT: Yale University Press, 1998.

Kestenbaum, Viktor. The Phenomenological Sense of John Dewey: Habit and Meaning. Atlantic Highlands, NJ: Humanities Press, 1977.

Roth, Wolff-Michael. Being and Becoming in the Classroom. Connecticut: Ablex Publishing, 2002.

Shuman, Robert. B. Classroom Encounters: Problems, Case Studies, Solutions. Washington, D. C.: National Education Association, 1989.

Stern, Robert. Hegel and the Phenomenology of Spirit. New York: Routledge, 2002.

\section{Notes}

1. In this work, the use of the term "consummatory experience," or "consummation," is based on Dewey's own articulation and use of it in Art as Experience, particularly in Chapter 3, "Having an Experience," 42-44.

2. Alexander, John Dewey's Theory of Art, Experience, and Nature: The Horizons of Feeling, 258.

3. Dewey, Art as Experience, LW 10:199. Note on citations to Dewey's works: Standard references to John Dewey's work are to the critical edition, The Collected Works of John Dewey, 1882-1953, edited by Jo Ann Boydston (Carbondale and Edwardsville: Southern Illinois University Press, 1969-1991), and published as The Early Works: 1882-1898 (EW), The Middle Works: 1899-1924 (MW), and The Later Works: 1925-1953 (LW). The numbers following refer to volume and page number.

4. Alexander, John Dewey's Theory of Art, Experience, and Nature: The Horizons of Feeling, 184.

5. Dewey, Art as Experience, LW 10:199.

6. Ibid., 42.

7. Ibid.

8. Alexander, John Dewey's Theory of Art, Experience, and Nature: The Horizons of Feeling, 200.

9. Dewey, Art as Experience, LW 10:42.

10. Ibid., 42-43.

11. Alexander, John Dewey's Theory of Art, Experience, and Nature: The Horizons of Feeling, 201.

12. Dewey, Art as Experience, LW 10:43-44.

13. Ibid.

14. Ibid., 45 . 


\section{Sevket Benhur Oral}

15. Ibid.

16. Alexander, John Dewey's Theory of Art, Experience, and Nature: The Horizons of Feeling, 201-202.

17. Dewey, Art as Experience, LW 10:47.

18. Kestenbaum, The Phenomenological Sense of John Dewey: Habit and Meaning, 1.

19. Ibid., 25 .

20. Stern, Hegel and the Phenomenology of Spirit, 28.

21. It might be objected that it is possible to be a public school teacher in contexts other than school classrooms. This is true. However, it is not my intention to provide an exhaustive analysis of all the possible places in which one can be a teacher. The point of the ensuing analysis is to discuss the situational characteristics (its holism and temporality) of the everyday lifeworld of public school teachers. A public school classroom as the most common physical environment inhabited by public school teachers serves our purposes. Any physical environment can be used to demonstrate Dewey's conception of the situational nature of experience. The situational nature of experience cannot be limited to any particular physical environment. Physical environment, any physical environment, is always encompassed within the inclusive integrity of experience. In other words, experience cannot be reduced to its physical component.

22. Dewey, "Qualitative Thought," LW 5:245.

23. Shuman, Classroom Encounters: Problems, Case Studies, Solutions, 9.

24. Jackson, John Dewey and the Lessons of Art.

25. Dewey, "Art in Education-and Education in Art," LW 2:111-15.

26. Gallagher, Hermeneutics and Education, 35.

27. Inwood, Heidegger: A Very Short Introduction, 31.

28. Dewey, Democracy and Education, MW 9.

29. Bloom, Postville: A Clash of Cultures in Heartland America.

30. Gadamer, Truth and Method, 3.

31. Alexander, John Dewey's Theory of Art, Experience, and Nature: The Horizons of Feeling, 107.

32. Dewey, Art as Experience, LW 10: 199.

33. Roth, Being and Becoming in the Classroom, 132.

34. Harman, Heidegger Explained: From Phenomenon to Thing.

35. Ibid., 31.

36. Ibid., 43.

Sevket Benhur Oral is at Ozyegin University in Istanbul, Turkey. E-mail: benhuroral@gmail.com 